\title{
Serum ferritin and vitamin D levels should be evaluated in patients with diffuse hair loss prior to treatment
}

\author{
Funda Tamer ${ }^{1}$, Mehmet Eren Yuksel², Yavuz Karabag ${ }^{3}$
}

1Department of Dermatology, School of Medicine, Ufuk University, Ankara, Turkey 2Department of General Surgery, School of Medicine, Aksaray University, Aksaray, Turkey ${ }^{3}$ Department of Cardiology, School of Medicine, Kafkas University, Kars, Turkey

Adv Dermatol Allergol 2020; XXXVII (3): 407-411 DOI: https://doi.org/10.5114/ada.2020.96251

\begin{abstract}
Introduction: Various factors like physiological and emotional stress, drugs and nutritional deficiencies can result in hair loss. Results of laboratory tests examining the underlying aetiology of hair loss vary in patients. Aim: We aimed to compare the serum levels of ferritin, folate, vitamin $B_{12}$, zinc, thyroid stimulating hormone and vitamin $D$ in patients complaining of diffuse hair loss and in healthy individuals.

Material and methods: Fifty-four patients with hair loss (47 females, 7 males) and 55 healthy individuals within the control group (47 females, 8 males) were included in this study. Serum levels of ferritin, folate, vitamin $B_{12}$, zinc, thyroid stimulating hormone and 25-hydroxyvitamin D were evaluated in all participants retrospectively.

Results: Serum concentrations of folate, vitamin $\mathrm{B}_{12}$, zinc and thyroid stimulating hormone were similar in the two groups. However, the mean serum ferritin and 25-hydroxyvitamin D levels were significantly lower in patients with hair loss than in healthy individuals. The mean serum ferritin levels of the patients and healthy individuals were $14.72 \pm 10.70 \mathrm{ng} / \mathrm{ml}$ and $25.30 \pm 14.41 \mathrm{ng} / \mathrm{ml}$, respectively. The mean serum 25 -hydroxyvitamin D levels of the patients and healthy individuals were $14.03 \pm 8.09 \mathrm{ng} / \mathrm{ml}$ and $17.01 \pm 8.59 \mathrm{ng} / \mathrm{ml}$, respectively. Eleven (20.4\%) patients had low serum ferritin levels, while 43 (79.6\%) patients had low vitamin D levels.

Conclusions: The results obtained from this study reveal that serum ferritin and 25-hydroxyvitamin D levels are generally low in patients complaining of hair loss. Therefore, serum ferritin and vitamin D levels should be evaluated and supplemented prior to treatment in all patients complaining of diffuse hair loss.
\end{abstract}

Key words: alopecia, hair loss, iron, vitamin D.

\section{Introduction}

Hair loss is a common complaint which can affect all ages and genders. Women usually visit dermatologists as a result of cosmetic concerns. Therefore, hair loss seems to be more common in women than in men [1]. The hair growth cycle consists of three distinct stages. These are anagen (growth phase), catagen (regression phase), and telogen (resting phase) [1, 2]. Various growth factors and receptors including insulin like growth factor 1 , fibroblast growth factor 7 , and hormones including oestrogens, androgens, thyroid hormones, glucocorticoids, retinoids, prolactin, and growth hormone play a role in regulating hair-follicle development and cycling [3]. Daily loss of 50-150 scalp hairs in the telogen phase is regarded as normal. However, an increasing percentage of telogen follicles results in excessive hair shedding [3]. Hair loss in the anagen stage is considered as abnormal since active hair-follicle growth is interrupted as in patients receiving chemotherapy $[1,3]$. Genetic predisposition, physiological stress, emotional stress, drugs, various medical conditions, and dietary deficiencies can lead to diffuse hair loss $[1,4]$. However, necessity of examining the nutritional status, and effect of supplements in the treatment of hair loss still remains controversial [4]. Evaluation of iron deficiency and thyroid hormone disorders is usually recommended in all patients with diffuse hair loss. However, the exact role of zinc deficiency in the aetiology of diffuse hair loss has not been proved [5]. Recently, it has been suggested that vitamin D deficiency could lead to diffuse hair loss [1].

\section{Aim}

The aim of this study is to compare the serum levels of ferritin, folate, vitamin $B_{12}$, zinc, thyroid stimulating

Address for correspondence: Asst. Prof. Funda Tamer, Department of Dermatology, School of Medicine, Ufuk University, Mevlana Bulvari, Konya Yolu, 86-88, Balgat, Ankara, Turkey, phone: +90 5455611881, e-mail: fundatmr@yahoo.com Received: 16.06.2018, accepted: 9.11.2018. 
hormone and vitamin D in patients with diffuse hair loss and in healthy individuals, to evaluate their role in the etiopathogenesis of hair loss.

\section{Material and methods}

This study included 54 patients who complain of diffuse hair loss and 55 healthy individuals within the control group who were admitted to the dermatology outpatient clinic between March 2016 and March 2017. Medical records of the participants were reviewed retrospectively.

The exclusion criteria were pregnancy, menopause, metabolic and endocrine disorders, hormone-replacement therapy, chemotherapy, immunosuppressive therapy, vitamin and mineral supplements, scarring alopecia, eating disorders and diet restrictions. Moreover, patients with female pattern hair loss usually have a positive family history, miniaturized hair, bitemporal recession, diffuse thinning over the mid-frontal scalp, wide midline part and preserved frontal hairline [6]. Therefore, patients with female pattern hair loss were also excluded from the study.

Laboratory tests of each participant including serum levels of ferritin, folate, vitamin $\mathrm{B}_{12}$, zinc, thyroid stimulating hormone (TSH) and 25-hydroxyvitamin D $(25(\mathrm{OH}) \mathrm{D})$ were evaluated.

Dermatological examinations of the scalp of the patients were normal, without any obvious abnormality. All the patients within this study had Fitzpatrick skin types III and IV.

The hair pull test was used to evaluate the severity of hair shedding [7]. Approximately 40 to 60 hairs were grasped between the thumb and forefinger, and grouped hairs were pulled gently until the end. Six or more hairs extracted from the scalp were regarded as positive [7].

\section{Statistical analysis}

Data were represented as mean \pm standard deviation or median for quantitative variables; counts and per-

Table 1. Laboratory test results of the participants

\begin{tabular}{|c|c|c|c|}
\hline Parameter & $\begin{array}{c}\text { Patients } \\
\text { Mean } \pm \text { SD }\end{array}$ & $\begin{array}{l}\text { Control group } \\
\text { Mean } \pm \text { SD }\end{array}$ & $P$-value \\
\hline Vitamin $B_{12}[\mathrm{pg} / \mathrm{ml}]$ & $291 \pm 233$ & $330 \pm 247$ & 0.18 \\
\hline Folate $[\mathrm{ng} / \mathrm{ml}]$ & $5.97 \pm 1.92$ & $6.07 \pm 2.29$ & 0.87 \\
\hline $\mathrm{TSH}[\mu \mathrm{IU} / \mathrm{ml}]$ & $1.32 \pm 0.96$ & $1.56 \pm 1.18$ & 0.10 \\
\hline Zinc $[\mu \mathrm{g} / \mathrm{dl}]$ & $84.90 \pm 21.80$ & $88.50 \pm 23.10$ & 0.41 \\
\hline Ferritin $[\mathrm{ng} / \mathrm{ml}]$ & $14.72 \pm 10.70$ & $25.30 \pm 14.41$ & $<0.001$ \\
\hline $25(\mathrm{OH}) \mathrm{D}[\mathrm{ng} / \mathrm{ml}]$ & $14.03 \pm 8.09$ & $17.01 \pm 8.59$ & 0.01 \\
\hline \multicolumn{4}{|c|}{$\begin{array}{l}\text { SD - standard deviation, TSH - thyroid stimulating hormone, } 25(\mathrm{OH}) \mathrm{D}- \\
25 \text {-hydroxyvitamin D. Serum vitamin } B_{12} \text {, folate, TSH and zinc levels were simi- } \\
\text { lar in patients and healthy individuals. However, serum ferritin and } 25(\mathrm{OH}) \mathrm{D} \\
\text { levels were significantly lower in patients when compared with the contro } \\
\text { group. }\end{array}$} \\
\hline
\end{tabular}

centage for categorical variables. Differences between 2 groups were tested with a t-test or Mann Whitney $U$ test for continuous variables and $\chi^{2}$ or Fisher exact tests as appropriate for categorical variables. The data were analysed using SPSS version 17.0 (SPSS Inc., Chicago, Illinois).

\section{Results}

Fifty-four patients with hair loss (47 females, 7 males) and 55 healthy individuals within the control group ( $47 \mathrm{fe}$ males, 8 males) were included in the study $(p=0.81)$. The mean age of the patients and control group was $24 \pm 6$ years and $23 \pm 6$ years, respectively $(p=0.59)$. The mean disease duration was $4 \pm 2$ months.

One $(1.9 \%)$ patient had leukonychia punctata and 2 (3.7\%) patients had onychoschizia on the fingernails. The past medical history was significant for seborrheic dermatitis in 2 (3.7\%) patients and hypertension in $1(1.9 \%)$ patient. The patient with hypertension was treated with oral valsartan $80 \mathrm{mg} /$ day over a year. Nine (16.7\%) patients stated irregular use of $2 \%$ topical minoxidil and hair loss shampoo previously. However, clinical improvement was not achieved in any patient. None of the patients had subjective symptoms like pruritus or pain. Eight (14.8\%) patients reported psychological stress as a triggering factor for the onset of hair shedding. The hair pull test was positive in 17 (31.5\%) patients.

The hair pull test helps to assess active hair loss. However, the hair pull test has low diagnostic sensitivity and specificity. It is both difficult to standardize the hair pull test and to perform it in patients with short hair [7]. Therefore, the hair pull test was positive in only 17 patients.

Laboratory tests of the participants revealed as stated below (Tables 1 and 2).

The mean serum ferritin level was $14.72 \pm 10.70 \mathrm{ng} / \mathrm{ml}$ in patients and $25.30 \pm 14.41 \mathrm{ng} / \mathrm{ml}$ in healthy individuals $(p<0.001$ ) (normal range is 10 to $204 \mathrm{ng} / \mathrm{ml}$ ). The serum ferritin level was decreased in 11 (20.4\%) patients while $43(79.6 \%)$ patients had normal serum ferritin levels. However, 5 (9.1\%) healthy individuals had a decreased serum ferritin level, while 50 (90.9\%) healthy individuals had normal serum ferritin levels $(p=0.09)$.

The mean serum vitamin $B_{12}$ level was $291 \pm 233 \mathrm{pg}$ / $\mathrm{ml}$ in patients, and $330 \pm 247 \mathrm{pg} / \mathrm{ml}$ in healthy individuals $(p=0.18$ ) (normal range is 190 to $880 \mathrm{pg} / \mathrm{ml})$. The serum vitamin $B_{12}$ level was decreased in $7(13 \%)$ patients while $47(87 \%)$ patients had a normal serum vitamin $B_{12}$ level. However, 4 (7.3\%) healthy individuals had a decreased serum vitamin $B_{12}$ level, while 51 (92.7\%) healthy individuals had normal serum vitamin $B_{12}$ levels $(p=0.33)$.

The mean serum folate level was $5.97 \pm 1.92 \% \mathrm{ng} / \mathrm{ml}$ in patients and $6.07 \pm 2.29 \mathrm{ng} / \mathrm{ml}$ in healthy individuals ( $p=0.87$ ) (normal range is 3.1 to $20 \mathrm{ng} / \mathrm{ml}$ ). The serum folate level was decreased in only 1 (1.9\%) patient. How- 
Table 2. Distribution of patients according to laboratory test results

\begin{tabular}{|c|c|c|c|c|c|c|}
\hline \multirow[t]{2}{*}{ Parameter } & \multicolumn{2}{|c|}{$\begin{array}{l}\text { Patients } \\
n(\%)\end{array}$} & \multicolumn{3}{|c|}{$\begin{array}{c}\text { Control group } \\
n(\%)\end{array}$} & \multirow[t]{2}{*}{$P$-value } \\
\hline & Low & Normal & Low & Normal & High & \\
\hline Vitamin $B_{12}$ & $7(13)$ & $47(87)$ & $4(7.3)$ & $51(92.7)$ & & 0.33 \\
\hline Folate & $1(1.9)$ & 53 (98.1) & $0(0)$ & $55(100)$ & & 0.31 \\
\hline TSH & $1(1.9)$ & 53 (98.1) & $1(1.8)$ & $53(96.4)$ & $1(1.8)$ & 0.56 \\
\hline Zinc & $5(9.3)$ & 49 (90.7) & $2(3.6)$ & $53(96.4)$ & & 0.23 \\
\hline Ferritin & $11(20.4)$ & 43 (79.6) & $5(9.1)$ & $50(90.9)$ & & 0.09 \\
\hline $25(\mathrm{OH}) \mathrm{D}$ & $43(79.6)$ & $11(20.4)$ & $39(70.9)$ & $16(29.1)$ & & 0.29 \\
\hline
\end{tabular}

TSH - thyroid stimulating hormone, $25(\mathrm{OH}) \mathrm{D}-25$-hydroxyvitamin D. The number of participants with low/normal levels of vitamin $B_{12}$, folate, TSH, zinc, ferritin and $25(\mathrm{OH})$ D were statistically similar in both groups.

ever, 53 (98.1\%) patients and all healthy individuals in the control group had normal serum folate levels ( $p=0.31$ ).

The mean serum TSH level was $1.32 \pm 0.96 \mu \mathrm{lU} / \mathrm{ml}$ in patients and $1.56 \pm 1.18 \mu \mathrm{UU} / \mathrm{ml}$ in healthy individuals ( $p=0.10$ ) (normal range is 0.4 to $4.2 \mu \mathrm{lU} / \mathrm{ml}$ ). The serum TSH level was decreased in 1 (1.9\%) patient, it was within normal limits in 53 (98.1\%) patients. The serum TSH level was decreased in 1 (1.8\%) healthy individual and it was increased in 1 (1.8\%) healthy individual. 53 (96.4\%) healthy individuals within the control group had normal serum TSH levels $(p=0.56)$.

The mean serum zinc level was $84.90 \pm 21.80 \mu \mathrm{g} / \mathrm{dl}$ in patients and $88.50 \pm 23.10$ in healthy individuals ( $p=$ 0.41 ) (normal range is 60 to $150 \mu \mathrm{g} / \mathrm{dl}$ ). The serum zinc level was decreased in 5 (9.3\%) patients and it was within normal limits in $49(90.7 \%)$ patients. The serum zinc level was decreased in 2 (3.6\%) healthy individuals and it was normal in 53 (96.4\%) healthy individuals within the control group $(p=0.23)$.

The mean serum 25(OH)D level was $14.03 \pm 8.09 \mathrm{ng} /$ $\mathrm{ml}$ in patients and $17.01 \pm 8.59 \mathrm{ng} / \mathrm{ml}$ in healthy individuals ( $p=0.016$ ) (normal range is 20 to $70 \mathrm{ng} / \mathrm{ml}$ ). The serum $25(\mathrm{OH}) \mathrm{D}$ level was decreased in $43(79.6 \%)$ patients, and it was within normal limits in 11 (20.4\%) patients. The serum 25(OH)D level was decreased in 39 (70.9\%) healthy individuals, and it was normal in 16 (29.1\%) healthy individuals within the control group $(p=0.29)$.

\section{Discussion}

Iron deficiency is the most common nutritional deficiency worldwide [8]. Both iron deficiency anaemia and iron deficiency without anaemia can be determined in patients with diffuse alopecia. Some of these cases do not respond to iron replacement therapy. However, in some patients oral iron treatment leads to cessation of hair loss and regrowth of the hair. Interruption of iron replacement makes these patients suffer from hair shedding again. Therefore, iron deficiency is regarded as a causative factor in patients with alopecia [9]. Hard investigated 96 female patients complaining of diffuse hair loss without any underlying skin disease. Eighteen of these patients had iron deficiency without anaemia. They were treated with oral iron supplements. All of the 18 patients stated that hair loss stopped during the follow-up $[8,10]$. Rasheed et al. compared serum ferritin and vitamin D levels of 80 female patients with chronic telogen effluvium and female pattern hair loss to 40 healthy individuals. Serum ferritin and vitamin D concentrations were significantly lower in patients than in control subjects [6]. Malkud evaluated the aetiological factors of diffuse hair loss in female patients. The study included 180 patients with telogen effluvium, chronic telogen effluvium, female pattern hair loss and anagen effluvium. Psychological stress and iron deficiency anaemia were reported as common underlying causes of telogen effluvium. However, chronic telogen effluvium was idiopathic in many cases [11].

In contrast, Bregy et al. evaluated serum ferritin levels of 181 women with female pattern hair loss and diffuse telogen effluvium. Trichogram was also performed in each patient to determine the telogen rate. No correlation was reported between serum levels of ferritin above $10 \mu \mathrm{g} / \mathrm{l}$ and telogen rates [12]. Sinclair et al. investigated 194 women with chronic diffuse telogen hair loss. Twelve (6\%) patients had serum ferritin of $20 \mu \mathrm{g} / \mathrm{l}$ or less. Scalp biopsy of 5 of 12 patients revealed normal histopathological features. Despite iron supplementation, cessation of hair loss was not observed in these patients [13].

The decreased serum ferritin level is a very specific finding of iron deficiency. Serum ferritin is regarded as the most valuable laboratory test for iron deficiency [8]. Within this study, the mean serum ferritin level was significantly lower in patients than in healthy individuals. Furthermore, a low serum ferritin level was observed more frequently in patients than in the control group. Our results indicate that serum ferritin concentrations may play a role in the etiopathogenesis of diffuse hair fall.

Zinc is an essential micronutrient that plays a role in protein and nucleic acid synthesis. It has been suggested that zinc inhibits hair regression and accelerates recovery of the hair follicle [14]. For instance, acrodermatitis 
enteropathica, a rare genetic disorder due to malabsorption of zinc clinically presents with hair loss [14, 15]. However, the association between zinc and hair loss is still controversial [14]. Kil et al. evaluated the serum levels of zinc and copper in patients with alopecia areata, male pattern hair loss, female pattern hair loss, telogen effluvium and healthy individuals. The serum level of zinc was significantly lower in patients than in healthy individuals. Patients who had serum zinc values lower than $70 \mu \mathrm{g} / \mathrm{dl}$ were more prevalent in the alopecia areata and telogen effluvium group. However, serum copper concentrations were similar between patients and healthy controls. Kil et al. suggested a possible role of zinc metabolism disturbances in the aetiology of hair loss [14]. Within this study, a mean serum zinc level was statistically similar in patients and the control group. A low serum zinc concentration was observed only in 5 patients and 2 healthy individuals. Our results have not revealed any correlation between serum zinc levels and hair fall.

Laboratory tests to assess thyroid dysfunction is recommended in patients with diffuse effluvium of unknown aetiology [16]. Deo et al. evaluated thyroid function tests in 135 females with telogen effluvium, alopecia areata, female pattern hair loss, frontal fibrosing alopecia and anagen effluvium. The most common alopecia type was telogen effluvium, followed by female pattern hair loss. Fourteen of 135 patients had previously known hypothyroidism or hyperthyroidism. Moreover, 5 patients had newly diagnosed hypothyroidism whereas 4 patients had hyperthyroidism. Therefore, Deo et al. suggested thyroid function tests to reveal subclinical thyroid disorders in women with hair loss [17]. Within this study, we observed a low serum TSH level in 1 patient and in 1 participant within the control group. Moreover, 1 participant within the control group had a high serum TSH level. Thyroid function disorders were not observed more frequently in the patient group when compared with the control group.

It has been suggested that vitamin $D$, vitamin $B_{12}$ and folate might play a role in the hair growth cycle. Cheung et al. evaluated serum levels of 25-hydroxyvitamin D, ferritin, vitamin $B_{12}$, folate, and zinc in 115 patients with telogen effluvium. Decreased serum ferritin, vitamin $D$ and zinc levels were reported in $45.2 \%, 33.9 \%$ and $9.6 \%$ of patients, respectively. Vitamin $B_{12}$ deficiency was stated only in $2.6 \%$ of patients. All the participants had normal serum folate concentrations [18]. Ozuguz et al. reported no statistically significant difference in serum levels of vitamin $B_{12}$ and folic acid between patients with chronic telogen effluvium and healthy individuals [19]. Within this study, the mean serum vitamin $B_{12}$ and folate levels were statistically similar in patients and healthy individuals. A low serum vitamin $B_{12}$ concentration was observed in 7 patients and 4 healthy individuals. Vitamin $B_{12}$ deficiency was observed at similar frequency in both groups. Furthermore, serum folate levels of the participants were all in normal limits except for 1 patient who had a low serum folate concentration.

Vitamin D is a steroid hormone synthesized in the epidermis via ultraviolet B exposure. It can also be obtained from diet and supplements. The role of vitamin D in the proliferation and differentiation of keratinocytes has been well established. Furthermore, it has been suggested that vitamin D might have an impact in hair growth and the hair cycle. Vitamin D receptors of the epidermal keratinocytes and mesodermal papilla cells increase in the late anagen and catagen phase. The progression of the hair cycle is thought to be associated with vitamin D receptors [20].

It has been suggested that decreased serum 25-hydroxyvitamin D levels might play a role in the etiopathogenesis of non-scarring alopecia. Vitamin D supplementation has been considered as the treatment of choice in patients with alopecia areata, female pattern hair loss, or telogen effluvium [21]. Similarly, topical application of vitamin $\mathrm{D}$ is reported to be helpful to prevent chemotherapy-induced alopecia [20].

Banihashemi et al. compared serum vitamin $\mathrm{D}_{3}$ levels of patients with female pattern hair loss to healthy women. Vitamin $D_{3}$ levels were significantly lower in the patient group. Banihashemi et al. suggested a relationship between decreased serum vitamin $D_{3}$ concentrations and incidence of female pattern hair loss. Therefore, Banihashemi et al. recommended to evaluate the serum vitamin $D_{3}$ level in cases with female pattern hair loss [22]. Rasheed et al. reported significantly lower serum 25-hydroxyvitamin D levels in females with chronic telogen effluvium and female pattern hair loss than in healthy controls [6]. Nayak et al. evaluated serum vitamin $D_{3}$ concentrations in 22 young adults complaining of diffuse hair loss. Vitamin D deficiency was significantly more frequent among patients when compared to healthy controls. The median value of serum vitamin $D$ was significantly lower among cases with diffuse hair fall [1]. Within this study, the mean serum 25(OH)D level was significantly lower in patients than in healthy individuals. However, we determined low serum 25(OH)D levels in $79.6 \%$ of the patients and in $70.9 \%$ of healthy individuals. Our results showed that the low serum vitamin D level was common in both patient and control group.

\section{Conclusions}

Since we have demonstrated significantly low serum levels of ferritin and $25(\mathrm{OH}) \mathrm{D}$ in the patient group, we suggest that serum iron and vitamin D status should be evaluated in all patients with diffuse hair loss prior to further treatment. Vitamin $B_{12}$ and zinc deficiencies were determined in a few patients. Therefore, it does not need to be mandatory to check vitamin $B_{12}$ and zinc levels routinely in every patient complaining of diffuse hair loss. 


\section{Conflict of interest}

The authors declare no conflict of interest.

\section{References}

1. Nayak K, Garg A, Mithra P, et al. Serum vitamin $D_{3}$ levels and diffuse hair fall among the student population in south India: a case-control study. Int J Trichology 2016; 8: 160-4.

2. Milner Y, Sudnik J, Filippi M, et al. Exogen, shedding phase of the hair growth cycle: characterization of a mouse model. J Invest Dermatol 2002; 119: 639-44.

3. Paus R, Cotsarelis G. The biology of hair follicles. N Engl J Med 1999; 341: 491-7.

4. Gowda D, Premalatha V, Imtiyaz DB. Prevalence of nutritional deficiencies in hair loss among Indian participants: results of a cross-sectional study. Int J Trichology 2017; 9: 101-4.

5. Shrivastava SB. Diffuse hair loss in an adult female: approach to diagnosis and management. Indian J Dermatol Venereol Leprol 2009; 75: 20-7.

6. Rasheed H, Mahgoub D, Hegazy R, et al. Serum ferritin and vitamin D in female hair loss: do they play a role? Skin Pharmacol Physiol 2013; 26: 101-7.

7. Olszewska M, Warszawik O, Rakowska A, et al. Methods of hair loss evaluation in patients with endocrine disorders. Endokrynol Pol 2010; 61: 406-11.

8. Trost LB, Bergfeld WF, Calogeras E. The diagnosis and treatment of iron deficiency and its potential relationship to hair loss. J Am Acad Dermatol 2006; 54: 824-44.

9. Sinclair R. Diffuse hair loss. Int J Dermatol 1999; 38: 8-18.

10. Hard S. Non-anemic iron deficiency as an etiologic factor in diffuse loss of hair of the scalp in women. Acta Derm Venereol 1963; 43: 562-9.

11. Malkud S. A hospital-based study to determine causes of diffuse hair loss in women. J Clin Diagn Res 2015; 9: WC01-4.

12. Bregy A, Trueb RM. No association between serum ferritin levels $>10$ microg/l and hair loss activity in women. Dermatology 2008; 217: 1-6.

13. Sinclair R. There is no clear association between low serum ferritin and chronic diffuse telogen hair los. Br J Dermatol 2002; 147: 982-4.

14. Kil MS, Kim CW, Kim SS. Analysis of serum zinc and copper concentrations in hair loss. Ann Dermatol 2013; 25: 405-9.

15. Puri N. A study on efficacy of oral zinc therapy for treatment of acrodermatitis enteropathica. Our Dermatol Online 2013; 4: $162-6$

16. Wolff H, Fischer TW, Blume-Peytavi U. The diagnosis and treatment of hair and scalp diseases. Dtsch Arztebl Int 2016; 113: 377-86

17. Deo K, Sharma YK, Wadhokar M, et al. Clinicoepidemiological observational study of acquired alopecias in females correlating with anemia and thyroid function. Dermatol Res Pract 2016; 2016: 6279108.

18. Cheung EJ, Sink JR, English lii JC. Vitamin and mineral deficiencies in patients with telogen effluvium: a retrospective cross-sectional study. J Drugs Dermatol 2016; 15: 1235-7.

19. Ozuguz P, Dogruk Kacar S, Ekiz O, et al. Evaluation of zinc, vitamin B12, folic acid and iron levels and thyroid functions in patients with chronic telogen effluvium. J Dermatol Res Ther 2015; 1: 1.

20. Amor KT, Rashid RM, Mirmirani P. Does D matter? The role of vitamin $\mathrm{D}$ in hair disorders and hair follicle cycling. Dermatol Online J 2010; 16: 3.
21. Gerkowicz A, Chyl-Surdacka K, Krasowska D, et al. The role of vitamin D in non-scarring alopecia. Int J Mol Sci 2017; 18: 2653.

22. Banihashemi M, Nahidi Y, Meibodi NT, et al. Serum vitamin D3 level in patients with female pattern hair loss. Int J Trichology 2016; 8: 116-20. 